\title{
Eram os poetas gregos arcaicos profissionais? Uma reavaliação da discussão sobre a profissionalização da atividade dos poetas gregos do período arcaico ${ }^{1}$
}

Roosevelt Rocha ${ }^{2}$

\begin{abstract}
Resumo: Neste texto faço uma série de críticas às propostas de Edmund Stewart sobre a profissionalização dos poetas gregos arcaicos. Ele defende que os poetas gregos sempre foram profissionais e sempre apresentaram sua atividade, em suas obras, como uma mercadoria que poderia ser vendida. Eu discordo dessa concepção, já que os poetas gregos não precisavam vender suas obras para sobreviver e eles não estavam em busca de ganhos materiais como compensação por suas atividades. Vários deles eram nobres e estavam interessados, na verdade, na perpetuação dos seus nomes, ou seja, no kleos, assim como os guerreiros e os atletas daquela época. Desse modo, pretendo demonstrar que o que levava o poeta a cantar, entre outras coisas, era o desejo de imortalizar-se através da poesia.
\end{abstract}

Palavras-chave: Poesia Grega Arcaica; Profissionalização; Pagamento; Dinheiro; Riqueza.

\begin{abstract}
In this text I make a series of criticisms of Edmund Stewart's proposals on the professionalization of archaic Greek poets. He argues that the Greek poets have always been professionals and have always presented their activity, in their works, as a commodity that could be sold. I disagree with this conception, since the Greek poets did not need to sell their works to survive and they were not seeking material gains as compensation for their activities. Several of them were noble and were actually interested in the perpetuation of their names, that is, in kleos, as were the warriors and athletes of that time. In this way, I intend to demonstrate that what led the poet to sing, among other things, was the desire to immortalize himself through poetry.
\end{abstract}

Keywords: Archaic Greek Poetry; Professionalization; Payment; Money; Wealth.

1 Uma primeira versão deste texto foi apresentada no dia 23 de janeiro de 2020 , num dos encontros do seminário 'Polythéisme et société : droit, rites, figuration', na salle Mariette, na Galerie Colbert, em Paris. Por isso preciso agradecer à professora Cléo Carastro e ao Professor Claude Calame pela oportunidade de apresentar e discutir algumas das minhas ideias. Quero agradecer também aos professores Pierre Judet de la Combe e Ágatha Bacelar pelas questões e sugestões. Quero aproveitar também para alertar o leitor para o fato de que este artigo tem um caráter programático, ou seja, há muitas discussões aqui que pretendo aprofundar em estudos que deverei realizar num futuro próximo. Agradeço também ao parecerista designado pela revista pelos comentários que me levaram a refletir sobre algumas questões importantes.

2 Doutor em Linguística pela Universidade Estadual de Campinas (Unicamp). Professor associado do Departamento de Linguística, Letras Clássicas e Vernáculas da Universidade Federal do Paraná (UFPR). Coordenador do projeto de pesquisa "Poesia, Música e Performance na Antiguidade Clássica". 


\section{Introdução}

É muito comum encontrar em manuais de História da Literatura Grega Antiga ou em livros clássicos sobre o mesmo tema a ideia de que os poetas gregos do período arcaico recebiam pagamento em troca dos seus 'produtos' poéticos. Simônides, por exemplo, ficou famoso por cobrar caro pelo seu trabalho e Píndaro também se notabilizou por causa de suas relações 'comerciais' com seus patronos ricos e poderosos que teriam pago altas somas de dinheiro a ele. Recentemente, Edmund Stewart, no seu livro Greek Tragedy on the move (2017, p. 13-17), defendeu essa abordagem, tentando demonstrar que a ideia da profissionalização não seria anacrônica. ${ }^{3}$ Contudo, pretendo apresentar aqui argumentos que mostram que os poetas gregos não estavam submetidos a uma concepção de trabalho semelhante à nossa maneira de pensar sobre esse tema. Em primeiro lugar, porque os poetas gregos eram pessoas de castas sociais elevadas (aristoi) e, por isso, não precisariam trabalhar para conseguir o seu sustento. Além disso, os poetas gregos, assim como os grandes guerreiros, atletas e potentados celebrados em suas obras, estavam em busca de honra e de glória. Por essa razão eles estabeleciam uma espécie de relação simbiótica com os personagens celebrados por eles através da xenia, que era uma espécie de amizade entre pessoas, geralmente, de cidades diferentes que pressupunha a troca de presentes. Nesse sentido, as canções funcionavam como dons e, em troca, o poeta poderia receber um contra-dom. Mas essa relação não era necessariamente uma relação comercial. Por isso, acredito que chamar os poetas gregos do século VI e da primeira metade do século $\mathrm{V}$ a. C. de profissionais é um anacronismo inaceitável.

Mas, antes de tratar especificamente desse tema, gostaria de apresentar aqui algumas ideias básicas importantes para esta discussão. Nos últimos anos, ao longo do meu trabalho de pesquisa, eu percebi que os poetas-músicos da Grécia Antiga nem sempre são caracterizados de maneira positiva. É verdade que, tradicionalmente, costuma-se destacar o papel de educador de Homero e de Hesíodo na cultura grega e o poder de perpetuação da memória muitas vezes é lembrado quando se fala da poesia na Grécia Antiga. Contudo, tenho desenvolvido pesquisas que me levaram a pensar que existe uma ambiguidade no modo como os gregos antigos concebiam a poesia e o poeta. Eles não são sempre vistos de maneira positiva, mas de forma ambivalente e, muitas vezes, de maneira negativa também. Ao estudar as odes e fragmentos de Píndaro, por exemplo, é comum encontrarmos menções ao modo como a poesia e o poeta são caracterizados em suas canções e é comum encontrarmos menções às relações que o poeta mantinha com seus patronos. A ideia básica é que Píndaro recebia encomendas para celebrar vitórias de atletas num dos grandes jogos da antiguidade grega e, em troca, o poeta receberia pagamento pelos seus serviços. Eu não concordo com essa caracterização e explicarei mais abaixo porque.

Recentemente, ao desenvolver pesquisas também sobre metapoesia e sobre o surgimento da crítica literária na Grécia Antiga, li o livro La parole et le marbre, de Jesper Svenbro. Nessa obra, o autor defende que Simônides e Píndaro eram poetas profissionais cuja "sophia poétique était à vendre: sa vente était la condition d'existence du poète" (SVENBRO, 1976, p. 175). ${ }^{4}$ Por esse motivo, os poetas corais se comparariam aos artesãos e

3 Cf. Budelmann (2018, p. 251, n. 35), que está de acordo com o que Stewart (2016) defende, ou seja, que os poetas gregos do período arcaico apresentavam a si mesmos como profissionais.

4 "A sophia (a habilidade, a sabedoria) do poeta estava à venda: sua venda era a condição da existência do poeta". 
para eles seus poemas seriam 'mercadorias' pelas quais os 'compradores' deveriam pagar o preço justo. Esse tipo de concepção já estava presente no livro Les Maîtres de la Vérité, de Marcel Detienne (1967, p. 106-110), que foi o orientador da tese de doutorado de Svenbro, a qual deu origem ao seu livro, e depois foram retomadas por Bruno Gentili (1984), em Poesia e Pubblico nella Grecia Antica. Na verdade, se quisermos traçar uma genealogia dessas ideias podemos remontar até os artigos que Gentili publicou em 1964 e 1965. Depois, o próprio Detienne, em seu livro, reconhece que suas ideias têm muita afinidade com as interpretações apresentadas por Gentili. Mais tarde o próprio Gentili (1984, p. 211, n. 31) cita o artigo de Gzella (1971), observando que ele faz uma leitura muito mecânica e inclinada para o biografismo, e cita também o livro de Svenbro. Essas ideias sobre o profissionalismo e sobre a comercialização da canção na Grécia Arcaica me causaram muito estranhamento e, por causa disso, procurei mais bibliografia sobre o assunto e encontrei um texto publicado recentemente, ou seja, o artigo de Stewart (2016) que trata desse tema.

Antes de abordar especificamente as propostas de Stewart, quero observar que ele utiliza os textos de Gentili, Detienne, Svenbro e Gzella para se contrapor a eles, mas também para citá-los como autoridades para defender suas ideias sobre a profissionalização do poeta na Grécia Antiga. Além desses autores, Stewart (2016, p. 201) cita também von Reden (1995, p. 30), mas de modo errôneo, dando a impressão de que a autora diz que a poesia "se tornou um bem comercial disponível para aquele que pudesse pagar por ele", mas essa ideia, na verdade, foi tirada da edição traduzida para o inglês do livro de Gentili (1988, p. 166). O que interessa é que Stewart defende que a poesia se tornou uma commodity ao mesmo tempo em que a arte do poeta se tornou a atividade de um especialista que lhe proporcionava seu meio de sobrevivência e isso é o que pode ser chamado de profissionalização. Desse modo, sem citar toda a bibliografia que Stewart usa, mas destacando os autores que me parecem os mais importantes para esta discussão, acredito que podemos traçar uma genealogia dessas ideias sobre a profissionalização da atividade do poeta a partir dos artigos de Gentili (1964 e 1965), passando por Detienne (1967), Gzella (1971), Svenbro (1976), Havelock (1982), chegando até o texto de Stewart (2016). ${ }^{5}$ Cada autor, à sua maneira, trata do tema e dá o seu toque pessoal à discussão: Detienne, por exemplo, defende a ideia de que houve uma secularização da poesia quando Simônides declarou sua independência em relação às Musas e quando relativizou os valores tradicionais. Havelock (1982, p. 290), por outro lado, partindo das suas reflexões acerca do processo de adoção da escrita no âmbito da cultura grega antiga, defende que a sophia do poeta se tornou um bem valioso em si, objetificado, quando ela passou a ser escrita e, a partir daí, passou a ser possível avaliá-la por meio do dinheiro. ${ }^{6}$

\section{As propostas de Stewart}

Tratemos então das propostas de Stewart. Em seu artigo de 2016, ele defende que o poeta, na Grécia dos períodos arcaico e clássico, era um profissional com uma habilidade específica, ou seja, uma tekhne. Sua profissão era sua ocupação principal e ele a praticava

5 Cf. também Bowra (1961, p. 308ss) e Lesky (1963, p. 210ss). Ver também Nagy (1989, p. 18-23), que não é citado por Stewart, mas já traz muitas ideias bastante afins à propostas por este último.

6 Cf. von Reden (1995, p. 32). 
com o objetivo de conseguir recompensas materiais (STEWART, 2016, p. 200-201). Thomas (1995, p. 119-122) e Bowie $(2009 ; 2012)$, por outro lado, já tinham defendido anteriormente que os poetas eram aristocratas que cantavam suas canções por outros motivos. Stewart, entretanto, afirma que os poetas apresentavam a si mesmos como parte de uma elite, mas eles reivindicavam também um status especial dentro desse grupo. De acordo com Stewart, o pertencimento a uma elite não exclui a possibilidade da profissionalização: um aristocrata poderia ter uma profissão. Além disso, com a introdução do uso da moeda, teria surgido uma nova classe média que poderia então 'consumir' poesia e pagar pela arte do poeta, já que então, na segunda metade do século VI e primeira metade do século V a. C., os 'produtos' dos poetas tinham se tornado commodities como outras quaisquer. Desse modo, a arte do poeta se tornou a ocupação de um especialista através da qual ele poderia garantir o seu sustento e isso é o que pode ser chamado de profissionalismo.

Stewart (2016, p. 204) se pergunta em seguida quando a profissionalização se tornou comum. Na Odisseia, os poetas, como os rapsodos mais tarde, parecem ser apresentados como 'artesãos especialistas' ou como 'profissionais'. Esse seria o caso de Fêmio, no Canto 1, e de Demódoco, no Canto 8. Contudo, o surgimento da ideia de profissionalismo é datada com mais frequência nas décadas finais do século VI e primeiras décadas do século V a. C., ou seja, no período em que viveram Simônides e Píndaro. Íbico e Anacreonte, porém, também poderiam ser considerados exemplos de poetas profissionais que trabalharam nas cortes de diversos potentados. Sólon e Teógnis, por outro lado, teriam sido os últimos autênticos amadores aristocratas.

De acordo com Bowie (2009, p. 134-135; 2012, p. 83), a relação que o poeta mantinha com sua audiência era caracterizada a princípio pelo costume da hospitalidade, isto é, a xenia, mais do que pela patronagem. O profissionalismo teria surgido mesmo só no final no século V, com o advento da Nova Música. Sobre isso, eu gostaria de defender que um possível tipo de profissionalismo teria surgido com o aumento do agonismo entre os gregos, acompanhado da introdução da premiação na forma de mercadorias (vasos com óleo de oliva nas Panateneias, por exemplo) e em 'dinheiro'. Um fato importante é a criação de grupos de profissionais como os Artistas de Dioniso e a existência de 'contratos de trabalho’ de músicos, encontrados no Egito, que datam dos períodos helenístico e imperial, e que foram estudados por Bélis (1999).

Stewart (2016, p. 202), contudo, defende que há mais sinais de continuidade do que de mudança no período arcaico, porque os poetas aludem com frequência a uma 'ideologia profissional'. Mas o que seria exatamente isso que Stewart está chamando de profissionalismo? Em primeiro lugar, o profissionalismo não seria um fenômeno moderno, posterior à Revolução Industrial. Na Odisseia (17, 384-386), por exemplo, já encontramos uma lista de profissões. Encontramos outras listas de ocupações e habilidades paralelas, nas quais poetas e/ou músicos são incluídos, em Hesíodo (Trabalhos e Dias, 25-26), Sólon (Sol. fr. 13, 43-62 West), Aristófanes (Nuvens, 331-334; Aves, 905-1057) e Platão (Apologia, 20c-22d; Fedro, 248d1-e2; Protágoras, 316d1-e3). ${ }^{7}$

Stewart (2016, p. 203-204) propõe também algumas reflexões sobre o modo como a habilidade específica do poeta afetava sua identidade e seu status como trabalhador na Antiguidade. Daí podemos nos colocar a seguinte questão: será que os aedos tinham uma

7 Cf. Stewart (2017, p. 15).

70 - Conexão Letras, Porto Alegre, v. 15, n. 24, p. 67-79, jul-dez. 2020. 
consciência de grupo ou mesmo uma 'consciência de classe'? ${ }^{8}$ De acordo com o estudioso, eles tinham um conhecimento especial e uma compreensão concedidos a eles pelas Musas que lhes permitia produzir suas composições. Citando Maslov (2009, p. 32-33), Stewart observa que os poetas arcaicos não se referem a si próprios como aoidoi, mas eles podem ter tido um tipo de 'auto-consciência coletiva'. Prova disso é o fato de terem existido organizações profissionais no período arcaico, como os Homéridas, de Quios, que talvez fosse um grupo de executores de poesia que tinham algum tipo de prática em comum e que alegavam descender do mestre lendário, ou seja, Homero. ${ }^{9}$ Houve também um grupo de poetas de Lesbos em Esparta e grupos de médicos e adivinhos, ou seja, profissionais com habilidades específicas organizados em linhagens familiares, como os Asclepíadas.

Outra coisa que caracteriza uma profissão é o domínio de uma habilidade específica, ou seja, uma tekhne. Essa palavra, porém, não é usada para caracterizar a arte do poeta na poesia épica antes do final do século VI, quando teria sido composto o Hino Homérico a Hermes, onde tekhne é usada em referência à arte de tocar a cítara e o aulo (v. 445, 465, $483,511)$. Contudo, metáforas artesanais relacionadas à poesia aparecem algumas vezes em Píndaro. ${ }^{10}$ Svenbro (1976, p. 187-188) já tinha dito que o conceito do poeta como artesão foi uma inovação característica do final do período arcaico, ligada à secularização da poesia na qual a habilidade (sophia) prescindia da inspiração divina. Mas uma estrita dicotomia entre habilidade e inspiração não teria sido universalmente reconhecida no período arcaico, segundo Stewart (2016, p. 207). As habilidades artesanais seriam dádivas divinas também e os poetas seriam tratados como iguais aos artesãos: Sólon (fr. 13W, 49-50) parece justapor o poeta que recebeu as dádivas das Musas e os artesãos pupilos de Atena e Hefesto. Como os artesãos, o cantor é tratado como um 'trabalhador público', um demioergos (cf. Odisseia, 17, 384-386). Contudo, a sophia do poeta não seria só comparável, mas mesmo superior às outras habilidades, como afirma Stewart (2016, p. 208).

Outro elemento que caracterizaria o trabalho do poeta é a viagem. De acordo com Stewart (2016, p. 209), as viagens garantiriam a empregabilidade contínua do poeta, já que cidades e patronos poderiam financiar somente um número limitado de festividades ao longo de um ano. Além disso, as viagens permitiam aos poetas alcançar audiências mais numerosas e aumentar a sua reputação. ${ }^{11} \mathrm{Ou}$ seja, os poetas poderiam viajar especificamente para participar de festivais onde eles poderiam receber prêmios e ganhar renome ou, quando estavam na situação de um exilado político, como teria sido o caso de Íbico e Anacreonte, eles poderiam se tornar poetas profissionais para conseguir seus meios de sobrevivência.

Então, em resumo, de acordo com Stewart (2017, p. 13-14), o que caracteriza o profissionalismo é: 1. uma prática regular numa ocupação paga; 2 . um conhecimento e um treinamento específicos; 3 . profissões podem desenvolver organizações para promover de modo mais efetivo os interesses do grupo; 4. profissionais ganham dinheiro por causa das suas habilidades; 5 . o profissional (tekhnites) é motivado por sua vocação para servir e beneficiar a sociedade através da prática da sua arte (por isso o aedo e os artesãos são

8 Thomas (1995, p. 118) demonstra que é um erro acreditar que os poetas gregos constituíam uma "classe coerente".

9 Na minha opinião, as evidências apresentadas por Stewart (2016, p. 207) são questionáveis: ele se baseia numa citação de Píndaro (Nemeia, 2, 1-3) e em escólios a essa passagem. É preciso nos perguntar: os Homéridas eram profissionais ou um grupo de cultuadores de uma figura heroicizada?

10 Pítica, 12, 6; Nemeia, 1, 25 e Peã, 9, 39. Cf. Stewart (2016, p. 207, nota 36).

11 Cf. Hino Homérico a Apolo, 166-173. 
chamados de demioergoi, 'trabalhador do povo', 'servidor da comunidade', na Odisseia, 17, 383); 6. o desejo de ser recompensado não precisa implicar que um profissional seja de um baixo extrato social ou exclui a possibilidade de outras fontes de renda. E aqui Stewart cita o fragmento 13 West, verso 71, de Sólon: "não há nenhum limite visível da riqueza para os homens". A questão é saber se Sólon diz isso de modo positivo ou se ele estava fazendo uma crítica aos homens ambiciosos em excesso. ${ }^{12}$

\section{Crítica à teoria da profissionalização}

Agora eu gostaria de fazer algumas críticas ao texto de Stewart e aproveitarei também para começar a esboçar as minhas propostas quanto ao tema da profissionalização. Stewart defende que não houve grandes mudanças de mentalidade ou na maneira como os poetas se apresentavam em seus textos. Eu acredito que houve, sim, mudanças no modo de pensar e de caracterizar a atividade do poeta-cantor no final do século VI e no começo do século V a. C., mas elas foram lentas, paulatinas, já que os gregos antigos não eram uma 'sociedade quente', para usar um termo cunhado por Lévi-Strauss. Ou seja, a cultura grega não era como a nossa, na qual as transformações tecnológicas estão intimamente ligadas a mudanças de mentalidade e de comportamento. Eu não diria, porém, que os gregos antigos eram uma 'sociedade fria', porque suas instituições políticas e seus hábitos de pensamento estavam claramente se transformando, desde o século VIII até o século IV a. C. Talvez, partindo das propostas de Lévi-Strauss, possamos dizer que os gregos antigos eram uma 'sociedade morna', na qual transformações importantes estão em curso, mas não num ritmo tão acelerado quanto numa 'sociedade quente' ${ }^{13}$

E aproveitando essa menção a um dos nomes mais importantes da Antropologia, penso que um dos problemas da argumentação de Stewart é que ele parece desprezar a importância das diferenças culturais e históricas que separam a cultura grega antiga da nossa. $\mathrm{Na}$ minha interpretação, os gregos antigos não estavam interessados na riqueza ou no dinheiro em si. $\mathrm{O}$ mais importante para eles era sobreviver à morte através do renome $\mathrm{e}$ permanecer na memória dos outros seres humanos, ou seja, o que interessava era a timé, o kleos, a doxa. Stewart utiliza termos modernos como commodity, money, professionalism sem colocá-los em perspectiva, sem modalizá-los. Para que esse anacronismo fique mais claro, penso que uma das tarefas ainda necessárias é investigar o que significa a palavra khrema, khremata. Acredito ser um problema traduzir essa palavra por 'dinheiro', por exemplo, já que nós já estamos acostumados com o papel moeda e esse tipo de coisa não existia na Grécia Antiga. ${ }^{14}$

Além disso, para que a poesia/música/canção fosse uma profissão, os poetas/aedos deveriam cantar/compor todos os dias ou com frequência para que isso lhes garantisse

12 Para uma discussão específica sobre o kerdos, ou seja, 'o ganho, o lucro', ver Descat (1986, p. 231) e Cozzo (1988, p. 58-71).

13 Lévi-Strauss trata, pela primeira vez, dos conceitos de 'sociedades frias'e 'sociedades quentes' numa entrevista concedida a Charbonnier (1959, p. 38). Esses conceitos serão retomados depois na sua lição inaugural no Collège de France, de 1960, e em outras obras. Além disso, para falar da cultura grega, talvez seja interessante também retomar o conceito de 'longa duração', de Fernand Braudel, já que as transformações do mundo material têm um efeito retardado sobre a mentalidade de um povo.

14 Sobre isso, ver Seaford (2014, p. 16 e 148).

72 - Conexão Letras, Porto Alegre, v. 15, n. 24, p. 67-79, jul-dez. 2020. 
seu sustento (biotos). Porém, isso, certamente, não acontecia. Os poetas eram solicitados principalmente em ocasiões especiais, como festivais religiosos e festividades familiares, como casamentos e funerais. Mas isso não acontecia todos os dias. Então podemos supor que os poetas não eram só poetas, mas desempenhavam outras funções, como os exemplos de Hesíodo (pastor), Arquíloco (mercenário) e Sólon (arconte) nos mostram.

Stewart utiliza acriticamente informações tiradas de escólios e de anedotas. Ele parece desconsiderar a teoria dos gêneros literários e parece tomar os textos poéticos como documentos históricos. E Lefkowitz (2012), já há algum tempo, alertou para os problemas que uma utilização indiscriminada dos escólios e de anedotas podem gerar, quando estudamos as biografias dos poetas gregos antigos. Quero deixar claro aqui que não estou preconizando uma desconsideração total das informações que encontramos nos escólios e nas anedotas. $\mathrm{O}$ que defendo é que é necessário reler os escólios de modo crítico para selecionar as informações que são verossímeis de acordo com os estudos mais recentes da cultura grega, especificamente aqueles que partem de uma metodologia antropológica, tal como a que encontramos nos textos de Calame. ${ }^{15}$

Os casos de Demódoco e Fêmio, na Odisseia, devem ser colocados em perspectiva. Demódoco é um aedo cego que está numa ilha de caráter fantástico, como os comentadores costumam frisar. ${ }^{16}$ Então talvez ele não represente fielmente um aedo real. Fêmio, por outro lado, está no palácio de Odisseu a contragosto: ele é forçado a cantar para os pretendentes, que estão ali numa situação excepcional.

Depois do artigo de 2016, Stewart publicou também um livro, em 2017, sobre o modo como a tragédia grega é um fenômeno panelênico e não só ateniense e como os tragediógrafos tinham hábitos comparáveis aos dos poetas do período arcaico, o que mostra que a tragédia é uma herdeira legítima da épica e da lírica, não só quanto às temáticas e quanto à performance, mas também do ponto de vista sociológico. Nesse livro, Stewart me parece tomar uma posição um pouco mais equilibrada, já que ele afirma que os poetas arcaicos constituíam um grupo de profissionais motivados pelo duplo objetivo de conquistar fama e recompensas materiais. ${ }^{17} \mathrm{Um}$ tema importante para Stewart é o fato de que os poetas viajam e a especialização e o profissionalismo podem explicar a tendência que os poetas e outros trabalhadores têm para viajar. Contudo, na minha opinião, ele exagera quando diz que a habilidade profissional seria uma commodity portátil (STEWART, 2017, p. 16) e que, nesse contexto, a xenia seria uma operação comercial (STEWART, 2016, p. 214). Ora, utilizar termos de uso comum no domínio dos estudos econômicos de hoje em dia é um anacronismo perigoso. Dizer que o poeta dependia da sua profissão para sobreviver também me parece um exagero.

Não estou em completo desacordo com Stewart e os outros estudiosos citados por ele. É evidente que havia uma certa especialização no período arcaico da história grega e acredito também que podemos dizer que havia profissões naquela época. Porém quero apresentar agora alguns argumentos que mostram que os poetas gregos não estavam submetidos a uma concepção de trabalho semelhante à nossa maneira de pensar sobre esse tema. Na minha interpretação, os poetas continuaram sendo apresentados como persona-

15 Cf. por último a terceira edição de Les Choeurs de jeunes filles en Grèce ancienne (2019), e também a bibliografia citada na página 608 .

16 O próprio Stewart (2016, p. 201, nota 6) cita o comentário de Stephanie West et alii à Odisseia ao tratar dessa questão.

17 Stewart (2017, p. 13). 
gens sagradas, seja em seus próprios poemas, seja em fontes secundárias. Isso é visível no famoso fragmento de Píndaro, no qual ele diz ser um "profeta da Musa". ${ }^{18}$ Nesse contexto, acredito ser interessante voltar ao livro de Svenbro (1976, p. 169-171) para demonstrar como um mesmo texto pode ser lido de maneiras diferentes: o relato acerca do roubo sofrido por Árion; o relato que conta como Íbico foi roubado e assassinado; e o relato que conta como Simônides escapou da morte na casa de Escopas. Esses textos podem ser usados para provar que os poetas recebiam ou exigiam uma boa remuneração pelo seu trabalho, mas também podem ser usados para demonstrar que os poetas eram figuras sagradas e protegidas pelos deuses, que castigavam os agressores sempre punindo-os com a morte.

Árion, ${ }^{19}$ que era da cidade de Metimna, na ilha de Lesbos, teria passado um tempo em Corinto, na corte de Periandro, tirano da cidade entre 625 e 585 a. C., de quem teria recebido muitas recompensas (khremata) por suas apresentações. Num dado momento, Árion teria decidido fazer uma viagem até a Sicília, onde teria acumulado mais riquezas. Em seguida, ele teria embarcado num navio de mercadores de Corinto para voltar para aquela cidade. No meio do caminho, os marinheiros decidiram roubar o tesouro do cantor e matá-lo para que ninguém soubesse. Árion, porém, pediu para cantar uma última canção. Ele vestiu sua roupa especial, cantou e lançou-se ao mar. Contudo, ele foi salvo por um golfinho e chegou à terra firme. Ele chega então a Corinto antes dos marinheiros e conta tudo a Periandro, que a princípio não acredita, mas em seguida descobre o que realmente aconteceu quando os marinheiros chegaram ao porto cidade. Outras fontes nos contam que o tirano mandou punir os marinheiros desonestos com a morte. O que quero destacar aqui é o fato extraordinário de Árion ser salvo por um golfinho, que podemos entender como uma intervenção divina, já que o golfinho é um animal constantemente associado a Dioniso e a Apolo. ${ }^{20}$

Com Íbico acontece algo semelhante, embora o poeta perca sua vida. ${ }^{21}$ Quando ele se encontrava numa praia deserta, ladrões tomaram todas as suas riquezas e o mataram. Mas, antes de morrer, ele viu uma 'nuvem de grous', os quais ele invocou como testemunhas do seu assassinato. Algum tempo depois, quando os ladrões se encontravam em Corinto, eles viram os grous que sobrevoavam a praia quando mataram o poeta e se gabaram em voz alta. Os habitantes do local ouviram-nos se gabar do crime e das riquezas roubadas e os castigaram com a morte. Mais uma vez vemos a intervenção de animais associados a divindades na narrativa, o que, mais uma vez, nos mostra que os poetas eram figuras protegidas pelos deuses, mesmo depois da morte.

Quanto a Simônides, a história que nos interessa aqui é aquela contada por Cícero, no De Oratore (II.86.352-3). Em resumo, Simônides estava no palácio de Escopas, na Tessália, aonde ele teria sido convocado para apresentar uma canção em homenagem ao soberano. Para embelezar sua composição, Simônides teria falado mais de Castor e Pólux

18 Cf. fr. 150 Snell-Maehler. Ver também o verso 6 do Peã 6 (52f Snell-Maehler = D6 Rutherford).

19 Cf. Heródoto, 1, 23-24.

$20 \mathrm{Cf}$. Hino Homérico 1, a Dioniso, no qual a divindade transforma em golfinhos os marinheiros que queriam fazer mal a ele. Ver também Hino Homérico a Apolo, no qual o deus se transforma num golfinho para levar os primeiros sacerdotes para o seu templo em Delfos (lembrando que o nome da cidade tem a mesma raiz de delphis, 'golfinho' em grego). Cf. também Cláudio Eliano, Sobre a natureza dos animais, 12. $45=$ fr. 939 PMG, que cita uma canção atribuída a Árion no qual ele fala dos golfinhos e agradece a Posídon por ele ter sido salvo por uma criatura do mar.

21 Anth. Pal. VII. 745 e Plutarco, Mor. 509f-10a. 
do que do homenageado e, por isso, Escopas, teria dito a Simônides que pagaria somente a metade do valor combinado e que o poeta deveria cobrar dos Dióscuros a outra metade. Pouco depois, alguém veio avisar a Simônides que dois rapazes o esperavam fora do palácio. Quando o poeta chegou na entrada do edifício, não encontrou ninguém. Subitamente o palácio desabou e isso causou a morte de todos que estavam dentro. Ou seja, o poeta foi salvo pelos deuses e o soberano avarento foi castigado com a morte. Mais uma vez vemos que o poeta é um personagem protegido pelas divindades.

Nesse sentido, acredito que precisamos repensar a ideia da 'dessacralização' da poesia, proposta por Detienne (1967, p. 106-110). Simônides é geralmente associado à avareza, ao 'amor pelo ganho' (philokerdia. Cf. Xenófanes, fr. 21DK). Ele teria sido o primeiro poeta a cobrar um pagamento pelo seu trabalho (ver Escólio a Aristófanes, Paz, 697b). Na sua Retórica (1391a10-12), Aristóteles conta que Simônides teria dito que "o sábio em geral frequenta as portas dos ricos". ${ }^{22}$ Gentili (1984, p. 211) propôs que, vivendo numa época em que os valores aristocráticos estavam sendo questionados e uma nova classe de artesãos e mercadores enriquecidos estava reivindicando mais poder na cidade, Simônides teria tratado suas composições como 'produtos〉 comercializáveis e que mereciam ser valorizados monetariamente. ${ }^{23}$ Contudo, mesmo com todas essas possíveis mudanças no modo de o poeta 'negociar' com o seu público, na minha opinião, ele não perdeu sua aura de sacralidade. E isso é perfeitamente visível na poesia de Píndaro em várias passagens, como nos fragmentos citados na nota 17 acima. Quero deixar claro aqui que não estou propondo que havia uma dicotomia absoluta entre sacralidade e comércio. O que defendo é que o tipo de relação que os poetas mantinham com seu público não pode ser descrita ou tratada como uma relação de comércio ou de trabalho como as que existem no mundo ocidental desde o final do século XVIII, pelo menos. Uma canção não era simplesmente um objeto dessacralizado e transmissível de uma pessoa para outra como uma mercadoria. Como outros 'produtos' que circulavam entre pessoas de alta casta, como trípodes, taças e vasos decorados, as canções tinham valor religioso e pedagógico e funcionavam como repositórios de elementos da tradição que precisavam ser preservados através da memória. E sabemos que a memória é uma faculdade altamente prezada e tratada como uma divindade na Grécia Antiga.

\section{O caso Píndaro}

Quanto à questão dos pagamentos recebidos por Píndaro, apresento a seguir um resumo da minha interpretação. Para compor suas canções, ele teria recebido encomendas. Alguns escólios e boa parte dos estudiosos modernos diz que seus patronos pagavam em dinheiro para o poeta pelo trabalho dele. Eu não penso dessa maneira. Não comentarei aqui em detalhe os famosos versos 6-12, da Ístmica 2. Contudo posso dizer que concordo, em geral, com Kurke, ${ }^{24}$ quando ela diz que os poetas poderiam receber pagamento, mas essa relação ainda era representada e compreendida dentro do quadro das relações aristocráticas de troca de dom e contra-dom. Por isso, acredito que as palavras misthos,

22 Cf. Platão, República, 489b-c e Diógenes Laércio, 2.69.

23 Sobre isso, cf. Ferreira (2013, p. 174-178) e Rawles (2018, p. 16-19), que se manifesta a favor da ideia de que Simônides recebia pagamento em troca de suas composições, mas reconhecendo que a discussão é complexa.

24 Ver especialmente os capítulos 4, 5, 6 e 10. 
khremata, kerdos e outras precisam ser reavaliadas a partir de uma visão antropológica e comparatista. Outros versos sempre evocados quando se fala da transformação da poesia em produto comercial são os 67-68, da Pítica 2, onde lemos que "essa canção, como mercadoria fenícia, é enviada sobre o mar cinza". Na minha interpretação, que se aproxima das de Descat (1986, p. 232-233) e de von Reden (1995, p. 42-44), quando o poeta usa a expressão 'mercadoria fenícia', ele não quer dizer que a canção é uma mercadoria, mas o que interessa é o fato de que ela viaja, se desloca, se movimenta.

Píndaro, na minha opinião, era um aristocrata e não precisaria de dinheiro para sobreviver. Se certas famílias importantes de alguns lugares do mundo grego precisavam de um poeta para celebrar suas conquistas, para o poeta, por sua vez, também era importante ter boas relações com essas famílias para que ele, da mesma forma, tivesse o seu nome perpetuado. Afinal, na cultura da Grécia Arcaica e mesmo Clássica, a reputação era algo determinante para todos ${ }^{25}$ Além do mais, é provável que Píndaro tivesse alguma relação de parentesco, mesmo que distante, ou amizade com, pelo menos, uma parte de seus patronos. Como disse acima, é possível que nosso poeta fosse um membro da família dos Egeidas, que tinha origens dóricas. ${ }^{26}$ Ora, havia fortes conexões entre a ilha de Egina e o mundo dórico. E Cirene teria sido fundada por colonos provenientes de Tera (hoje Santorini), que, por sua vez, teria sido colonizada por pessoas de origem dórica. O que estou tentando sugerir é que parece ter havido uma 'conexão dórica' que pode explicar, pelo menos em parte, a lógica das relações que Píndaro tinha com seus patronos. ${ }^{27}$

Além disso, Píndaro, em vários momentos, parece falar de si como um xeinos, como alguém que tinha uma relação de xenia com seus patronos. ${ }^{28}$ Isso quer dizer que ele era um estrangeiro, mas que tinha algum tipo de relação de amizade com as pessoas da cidade de onde vinha o vencedor. Se isso for verdade, algo que era necessário entre xeinoi era a troca de presentes. Se Píndaro oferecia seu poema ao vencedor, este certamente retribuia com vasos, trípodes, vinho, azeite ou mesmo objetos feitos de algum metal precioso. Tudo isso é possível. Porém tratar a xenia como uma relação comercial em termos modernos é, no mínimo, inadequado. ${ }^{29}$

\section{Uma rápida comparação}

Para terminar gostaria de comentar rapidamente alguns trechos de um livro que li há pouco tempo e que trata de questões importantes para nós aqui. É bom lembrar que este texto foi apresentado, pela primeira vez, num centro de estudos, o antigo Centre Gernet-Glotz, hoje ANHIMA, onde o Comparatismo é o método preconizado para o desenvolvimento de pesquisas que enriquecem as nossas reflexões. O livro em questão é

25 Sobre isso, cf. Teógnis (237-254 West); Íbico: “Tu também, Polícrates, glória imortal terás/ como, por causa do meu canto, também minha glória será imortal” (S151, 47-48 PMGF); e Píndaro, Pítica 3, 114-115: "A excelência com gloriosas canções é durável".

26 Cf. Pítica 5, 75-76.

27 Méautis (1962) propôs uma interpretação semelhante, mesmo que recusada por Briand (2003, p. 204).

28 Cf. Nemeia 7, 61 e Nemeia 9, 2. Para mais exemplos dos usos que Píndaro faz de palavras como xenia e correlatas, cf. Slater (1962, p. 357-358).

29 Sobre isso, ver Kurke (2013, p. 119-139); Peliccia (2009, p. 243-247); Bowie (2012, p. 83-92) e Morgan (2015, p. 115-119). 
Dossiê H, do escritor albanês Ismail Kadaré. A grosso modo, esse texto conta a história de Milman Parry e Albert Lord, fazendo, é claro algumas adaptações. No prefácio ao livro, ficamos sabendo que Kadaré conheceu Lord em Istambul e teve uma conversa rápida com ele sobre as pesquisas que ele e Parry iriam realizar na Sérvia. Daí Kadaré teria tirado a ideia de escrever sobre pesquisadores que vão para a Albânia para estudar a poesia épica oral ainda existente naquele país no começo do século XX. O que nos interessa aqui é que, em dois momentos, encontramos a informação de que os poetas orais albaneses não recebiam pagamento para recitar seus poemas: "Conformément à la vieille coutume, il n'acceptait aucune rétribuition. Il fut seulement entendu qu'il ne paierait pas le prix de cette nuit passée à l'auberge" (KADARÉ, 1996, p. 439);0 “...les rhapsodes albanais n'acceptaient aucune sorte de gratification..." (KADARÉ, 1996, p. 455). ${ }^{31}$ Quando li pela primeira vez essas linhas, julguei que, se isso fosse verdade e se eu pudesse confirmar isso comparando com as informações que poderia encontrar nos livros de Parry (1971) e Lord (1971), a narrativa de Kadaré poderia me ajudar a confirmar minhas hipóteses sobre a não comercialização e a sacralidade da poesia entre os gregos antigos, ainda mais tendo em vista que essa poesia albanesa, como a sérvia, poderia conservar certos traços da antiga poesia grega. Uma nota no livro de Parry (1971, p. 330-331, nota 2) nos informa, entretanto, que, em alguns países, a arte do cantor era uma profissão paga. Mais adiante (PARRY, 1971, p. 335, nota 1), contudo, ficamos sabendo que, em Sarajevo, um cantor, que se considerava o melhor, não aceitava recompensas. Lord (1971, p. 15-18) também nos conta que os cantores sérvios recebiam pagamentos em dinheiro ou em grãos, alguns deles eram bastante procurados, mas outros tinham outras fontes de renda. Ora, isso parece indicar que Kadaré trata de um fenômeno específico da Albânia ou então ele estava retratando de modo idealizado os cantores do seu país, com o objetivo de afirmar a superioridade moral desses pastores que viviam nas montanhas.

\section{Conclusão}

Que conclusão podemos então tirar de tudo isso? Penso que devemos tratar a Grécia Antiga com um olhar antropológico, reconhecendo as diferenças e tomando muito cuidado para não cair no anacronismo. Nós seremos sempre anacrônicos, mas precisamos tentar nos distanciar o máximo possível da nossa própria cultura e do nosso próprio modo de pensar para tentar entender os outros povos que têm visões muito diferentes e lidam de modos muito diversos com objetos e palavras que para nós parecem ter os mesmos significados que os nossos objetos e as nossas palavras de hoje em dia. Essa tendência de tratar a atividade do poeta como uma profissão tem, para mim, um conteúdo calvinista-marxista que preconiza a ideia de que o trabalho dignifica e o trabalhador é alguém que tem muito valor. Não discordo disso. Mas acredito que os gregos antigos não pensavam assim. É bastante conhecida a desvalorização das atividades manuais entre os gregos ${ }^{32}$

30 "De acordo com o antigo costume, ele não aceitava nenhuma retribuição. Mas ficou combinado que ele não pagaria aquela noite passada no albergue".

31 "Os rapsodos albaneses não aceitavam nenhum tipo de gratificação".

32 Para uma introdução a essa discussão ver Anastasiadis (2004, p. 58-59). Ver também Verboven (2014), que faz um resumo das discussões sobre o modo como o trabalho e os trabalhadores são avaliados na Antiguidade Clássica. 
e a aproximação entre poesia e artesanato poderia nos levar a pensar justamente que a primeira está sendo desvalorizada ao fazermos essa comparação. Ford (2002, p. 93-157) e Bouvier (2003, p. 93-94) demonstraram que os poetas gregos não chamavam a si próprios de 'poetas'. Quem fez isso foram Heródoto, os Sofistas, Platão e Aristóteles. Desse modo, os cantores do período arcaico, provavelmente, não aceitariam ser comparados a trabalhadores braçais como os artesãos. Além disso, a ideia da 'dessacralização da poesia', defendida por Detienne, poderia nos levar a pensar numa transformação repentina da mentalidade grega, algo que se aproxima das antigas concepções do Milagre Grego, tão condenadas pela Escola de Paris (Vernant, Vidal-Naquet, Detienne). É preciso colocar Simônides e Píndaro dentro do processo, não isolá-los. Acho que Stewart até tenta fazer isso, mas sua abordagem é anacrônica.

\section{Referências}

ANASTASIADIS, V. I. Idealized $\sigma \chi 0 \Lambda \eta ்$ and disdain for work: aspects of philosophy and politics in ancient democracy. The Classical Quarterly, v. 54, n. 1, 2004, p 58-79. BÉLIS, Annie. Les musiciens dans l'Antiquité. Paris: Hachette-Littératures, 1999.

BOUVIER, David. Quand le poète était encore un charpentier... aux origines du concept de poésie. Études de Lettres, n. 3, 2003, p. 85-105.

BOWIE, Ewen. Wandering poets, archaic style. In: HUNTER, Richard L.; RUTHERFORD, Ian (eds.). Wandering poets in ancient Greek culture. Cambridge: Cambridge University Press, 2009, p. 105-136.

. Epinicians and patrons. In: AGÓCS, Peter; CAREY, Christopher; RAWLES, Richard (eds.). Reading the Victory Ode. Cambridge: Cambridge University Press, 2012, p. 83-92.

BOWRA, Cecyl Maurice. Greek lyric poetry. Oxford: Oxford University Press, 1961. BRIAND, Michel. Le vocabulaire de l'excelence chez Pindare. Revue de Philologie, t. LXXVII, n. 2, 2003, p. 203-218.

BUDELMANN, Felix. Lyric minds. In: BUDELMANN, Felix; PHILIPPS, Tom (eds.). Textual events: performance and the lyric in early Greece. Oxford: Oxford University Press, 2018, p. 235-256.

CALAME, Claude. Les choeurs de jeunes filles en Grèce ancienne. Paris: Les Belles Lettres, 2019.

CHARBONNIER, Georges. Entretiens avec Claude Lévi-Strauss. Paris: Plon-Julliard, 1959.

COZZO, Andrea. Kerdos: semantica, ideologie e società nella Grecia antica. Roma:

Edizioni dell'Ateneo, 1988.

DESCAT, Raymond. L'acte et l'effort: une idéologie du travail en Grèce ancienne (8ème - 5ème siècle av. J.-C.). Besançon: Université de Franche-Comté, 1986.

DETIENNE, Marcel. Les maîtres de vérité dans la Grèce archaïque. Paris: Maspero, 1967.

FERREIRA, Luísa de Nazaré. Mobilidade poética na Grécia Antiga: uma leitura da obra de Simónides. Coimbra: Imprensa da Universidade de Coimbra, 2013.

FORD, Andrew. The origins of criticism. literary culture and poetic theory in Classical Greece. Nova Jérsei: Princeton University Press, 2002. 
GENTILI, Bruno. Studi su Simonide II: Simonide e Platone. Maia, n. 16, 1964, p. 278-306. . Aspetti del rapporto tra poeta, committente, uditorio nella lirica corale greca.

Studi Urbinati, n. 39, 1965, p. 70-88. za, 1984.

. Poesia e pubblico nella Grecia Antica: da Omero al V secolo. Roma-Bari: LaterPress, 1988.

GZELLA, Stalislaw. The problem of the fee in Greek choral lyric. Eos, n. 59, 1971, p. 189-202.

HAVELOCK, Eric A. The literate revolution and its cultural consequences. Nova Jérsei: Princeton University Press, 1982.

KADARÉ, Ismail. Oeuvres: tome quatrième. Paris: Fayard, 1996.

KURKE, Leslie. The traffic in Praise. Berkeley: California Classical Studies, 2013.

LEFKOWITZ, Mary R. The lives of the Greek poets. Baltimore: The Johns Hopkins University Press, 2012.

LESKY, Albin. Geschichte der Griechische Literatur. Bern-München: Francke, 1963.

LORD, Albert B. The singer of tales. New York: Atheneum, 1971.

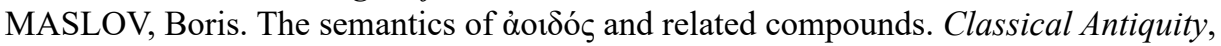
v. 28, n. 1, 2009, p. 1-38.

MÉAUTIS, Georges. Pindare le Dorien. Neuchâtel-Paris: La Baconnière-Albin Michel, 1962.

MORGAN, Kathryn A. Pindar and the construction of Syracuse monarchy in fifth century B. C. Oxford: Oxford University Press, 2015.

NAGY, Gregory. Early Greek views of poets and poetry'. In: KENNEDY, George A. (ed.). The Cambridge history of literary criticism. Cambridge: Cambridge University Press, 1989, p. 1-77.

PARRY, Milman. The making of Homeric verse. Oxford: Clarendon Press, 1971.

PELLICCIA, Hayden. Simonides, Pindar and Bacchylides. In: BUDELMANN, Felix (ed.), The Cambridge Companion to Greek lyric. Cambridge: Cambridge University Press, 2009, p. 240-262.

RAWLES, Richard. Simonides the poet: intertextuality and reception. Cambridge: Cambridge University Press, 2018.

SLATER, William J. Lexikon to Pindar. Berlin: De Gruyter, 1969.

STEWART, Edmund. Professionalism and the poetic persona in Archaic Greece. The Cambridge Classical Journal, v. 62, 2016, p. 200-223.

. Greek tragedy on the move: the birth of a Panhellenic art form c.500-300 BC.

Oxford: Oxford University Press, 2017.

SVENBRO, Jesper. La parole et le marbre: aux origines de la poétique grecque. Lund:

Studentliteratur, 1976.

THOMAS, Rosalind. The place of the poet in archaic society. In: POWELL, Anton (ed.). The Greek world. London: Routledge, 1995.

VERBOVEN, Koenraad. Attitudes to work and workers in Classical Greece and Rome.

Tijdschrift voor Economische en Sociale Geschiedenis, v. 11, 2014, p. 67-87.

VON REDEN, Sitta. Deceptive readings: poetry and its value reconsidered. The Classical Quarterly, v. 45, n. 1, 1995, p. 30-50. 